\title{
A PROPÓSITO DE REDES DE RELAÇÕES NAS GUIANAS*
}

\author{
Peter Rivière, Denise Fajardo Grupioni, Dominique Tilkin Gallois, \\ Gabriel Barbosa, Renato Sztutman, Rogerio Duarte do Pateo
}

\section{Peter Rivière}

Quando me aposentei, há uns cinco anos, decidi que também era tempo de parar de escrever resenhas de livros - ao longo de quase 40 anos elas foram muitas, principalmente de etnografias sul-americanas. Isto, até que me chamou a atenção o livro aqui examinado. É provavelmente um erro sair do recolhimento, mas sinto que esse volume merece resposta, especialmente no Brasil.

Devo dizer que a princípio iniciei a leitura com alguma predisposição a favor da coletânea, já que freqüentes vezes reclamei maior ênfase em estudos comparativos nas Terras Baixas da América do Sul, e um volume justamente dedicado a isso deveria certamente ser bemvindo. Mas temo que não seja esse conforme explicitarei adiante - o modo de realizar o intento.

Os principais objetivos do Projeto Temático Sociedades Indígenas e suas Fronteiras na Região Sudeste das Guianas (doravante, PTG) são enunciados pela coordenadora Dominique Gallois na Introdução ao volume. São eles, resumidamente: 1. superar o recorte localista; 2. superar o recorte étnico; 3 . estudar essas relações intercomunitárias; 4. superar recortes geográficos. São intentos admiráveis, ainda que ambiciosos. No entanto, em cada um deles o que se quer realmente superar são os supostos pecados e as omissões dos etnógrafos dos anos 1960 e 1970; nós (sou um desses etnógrafos) aparentemente não vimos bem as coisas e estávamos simplesmente errados. O ataque é incessante e soma-se à recusa em sequer considerar as mudanças que ocorreram na região no último quarto de século. $\mathrm{O}$ sucesso um tanto autocomplacente do PTG vem de investir contra um homem-de-palha, um oponente de encomenda. Não reconhecer, ou compreender mal, aquilo que está na literatura resultou em algo designado "tipo ideal" guianense sociedades minimalistas, voltadas para si próprias, com interações externas limitadas. Esta é uma noção construída pelos membros do PTG; nenhum dos autores por eles criticados utiliza tal conceito, exceto Henley (1996), que fala em "tipo ideal", porém referindo-se apenas à estrutura de terminologias de parentesco.

Começarei com alguns exemplos simples do tipo de distorção que caracteriza este livro. Segundo Gallois, em meu livro, Individual and society in Guiana (Rivière 1984; doravante, ISG) ${ }^{1}$, eu teria preferido "descartar os Yanomami, em função de seu complexo sistema multicomunitário" (:16, papagueado por Sztutman:168). Isto se encaixa bem em 
seu argumento, mas não é certamente a razão que apresentei para excluir os Yanomami do estudo. Escrevi que eles "compõem-se de uma quantidade de subgrupos, entre os quais há considerável variação. Alguns desses subgrupos apresentam organização social muito similar à de mais povos da Guiana, ao passo que outros subgrupos têm aspectos não encontrados alhures. Além disso, o tamanho, bem como a variação, faz dos Yanoama um objeto extremamente apropriado para um estudo em separado" (1984:2)

Gallois também declara que a abordagem adotada pelo PTG tornou "a região menos 'anômala' em relação às demais áreas etnográficas amazônicas" (:19); uma frase que sugere que essa anomalia é devida aos estudos anteriores (cujos autores não são especificados). A afirmação causou-me estranheza, já que tanto em ISG quanto no Prefácio à edição brasileira eu me dou ao trabalho de deixar marcado que a Guiana é uma entidade puramente artificial, isolada para propósitos analíticos, e que é clara e distintamente reconhecível como parte de uma cultura mais vasta das Terras Baixas Sul-Americanas. Ademais, é de se perguntar se Sztutman poderia escrever que: "a distância sociológica existente entre as sociedades que habitavam as Guianas até pelo menos o século XVIII e os grupos pretensamente atomistas contemporâneos parece menos acentuada quando uma série de aspectos estruturais, revelados pela etnologia produzida sobre a região, são levados em conta" (:146), caso tivesse lido o que Henley (1996:47) já afirmara: "Além do mais, como premissa metodológica geral, eu argumentaria que, não raro, pode ser um erro estabelecer distinção rígida e apressada entre organizações sociais pré e pós-colombianas na Amazônia. No que concerne à orientação predominante na Amazônia, a invasão européia certamente levou à destruição as redes sociais, econômicas e políticas indígenas mas, no devido tempo, quando foram superados os efeitos de holocausto trazidos pelas novas doenças e pela escravização, tais redes foram substituídas por outras, híbridas, que incorporavam tanto componentes mestiços quanto indígenas".

A posição assumida pelo PTG ao longo do trabalho parece especificamente concebida para acentuar nas etnografias anteriores aqueles aspectos em que o "tipo ideal" é construído, e para abafar outros, aqueles que são o foco principal do Projeto. Esta estratégia faz suas idéias e seus achados parecerem muito mais originais do que as dos predecessores. No entanto, se há um "tipo ideal", ele é a imagem ideal que os próprios povos da Guiana mantêm; aquilo que muitos etnógrafos descreveram como ideais nativos, que representam a comunidade como autônoma e auto-suficiente e constituem uma perspectiva que, conforme aqueles mesmos etnógrafos invariavelmente observaram, é uma ficção. O estado ideal não é alcançável - por motivos econômicos, demográficos, sociais e rituais. As etnografias estão repletas de relatos a respeito de trocas, casamentos, rituais e outras instituições que resultam em e facilitam a interação entre povoamentos (settlements). O assunto é claramente explicitado no capítulo 6 de ISG, intitulado "Autonomia e dependência". Com efeito, seu primeiro parágrafo não poderia, a meu ver, ser mais claro a esse respeito (mas bem sei que é impossível esclarecer algo a ponto de garantir que ninguém será capaz de entendê-lo mal).

O capítulo de Denise Fajardo Grupioni, "Tempo e espaço na Guiana indígena" ocupará mais que os outros minha atenção aqui, pelo simples fato de que lida principalmente com os Tiriyó, sobre os quais tenho mais a dizer. Mesmo assim, não há espaço para comentar tudo o que 
eu gostaria. O que fazer de sua alegação (:37) de que o PTG tenta operar com conceitos indígenas, como se este não fosse o princípio fundamental da antropologia social desde o início do século XX? $\mathrm{Na}$ verdade, para voltar a me referir a ISG, afirmo que a comparação aí foi conduzida em termos de categorias nativas, exceto quanto às formações sociais que o observador pode identificar, mas que não chegam a receber designação na língua nativa (:6-7).

Entre os Trio, há duas formações sociais importantes para as quais não há termo nativo: a família e aquilo que chamei de aglomeração - uma coleção de povoamentos no âmbito dos quais há um padrão particularmente denso de relações genealógicas e conjugais. ${ }^{2}$ Além disso, enfatizo aí a importância de reconhecer o contexto social mais amplo no qual um povoamento específico está contido. O conceito tiriyó enfocado por Grupioni é itüpü, que ela traduz por "continuação". Ela afirma que as itüpü são grupos nomeados ("cada itüpü possui uma denominação própria"), definidos por "um princípio de descendência paterna" e que trocam esposas ("os membros de uma itüpü privilegiam a busca de casamentos exogâmicos com membros de outras itüpü"). Tal afirmação é tão discrepante em relação ao que descrevo em Marriage among the Trio (1969) (doravante, MATT) e em outros trabalhos que fica impossível deixá-la passar sem menção. Aqui, admito a séria desvantagem de não ter tido acesso à tese de doutorado de Grupioni. ${ }^{3}$ Suponho, no entanto, que contenha todos os dados genealógicos necessários para sustentar a sua alegação. Ainda assim, é preciso cautela, pois para qualquer instância de casamento entre primos cruzados reais é possível mostrar que está em jogo uma troca entre duas linhas de descendência. Na verdade, é dessa forma que se traça o diagrama convencional de casamento entre primos cruzados. Os dados genealógicos que eu mesmo recolhi mostram vários desses casos, mas as pessoas neles envolvidas não formam linhagens unilineares que trocam esposas. A maior parte de meus dados genealógicos foi publicada, e essa informação, portanto, está disponível para quem quiser submetê-la a novas análises e provar a existência de tais grupos. O que posso dizer é que não os encontrei.

Embora Grupioni nada mencione a respeito, duas páginas de MATT (1969:6465) são dedicadas à discussão sobre as itüpü, ou itïpïme, na minha transliteração. ${ }^{4}$ A autora está correta em traduzir o termo por "continuação" (embora também signifique "continuar"), mas não menciona o fato de que ele tem um emprego amplo e mais corriqueiro fora do contexto do parentesco. Citarei meu trabalho: "Pode significar 'continuar sem pausa', como, por exemplo, para descrever dois terrenos contíguos sem descontinuidade ou fronteira entre eles. Pode ser aplicado para falar de alguém que passa por um lugar a caminho de outro, sem se deter, ou apenas brevemente". Em seguida, enfatizo sua natureza relativa quando usado para descrever relações; em outras palavras, o filho de um homem é mais itïpïme do que o filho de sua irmã, mas este por sua vez é mais itïpïme do que o filho de um não-parente. O termo pode ser usado para descrever qualquer laço consangüíneo, vertical ou horizontal, razão pela qual o traduzi, no contexto do parentesco, como relação genealógica.

Por temer que houvesse alguma incompreensão de minha parte, consultei Eithne Carlin e Cees Koelewijn para saber como entendiam a palavra. Ambos concordam com a glosa que propus em MATT, embora Carlin tenha acrescentado que a palavra tem de ser empregada em associação com outro substantivo. 
Assim, não se fala simplesmente de uma itïpï, uma continuação, mas aí deve existir um modificador, por exemplo, Aramayana itïpï, uma continuação aramayana. Nenhum dos dois ouviu o termo ser empregado no sentido que lhe dá Grupioni, nem ele assim aparece na coleção de mitos de Koelewijn, de 1987, na qual certamente seria de se esperar que o encontrássemos. Quando levantei a questão, Carlin estava indo passar algumas semanas entre os Trio e dispôs-se a averiguar melhor sobre o assunto. Após indagar de vários Trio, ela chegou à conclusão de que imoitï (afins, co-residentes) e itïpï são basicamente sinônimos. ${ }^{5}$ Fato que traz outro problema para Grupioni, uma vez que ela contrasta imoitï e itïpï como representação das coordenadas sociais dos Trio para, respectivamente, espaço e tempo, isto é, co-residência e descendência.

Creio que ela tenha equivocadamente reificado um termo que expressa uma relação; grupos de descendência foram assim criados a partir do reconhecimento de continuidade genealógica. Na sociedade ocidental, se perguntarmos a um homem se ele reconhece uma "continuidade" (i.e., descendência) em relação a seu pai e a seu filho, é quase certo que tenhamos uma resposta positiva. Mas nem por isso consideramos que essa continuidade genealógica forme um grupo de descendência e, assim, podemos sem problemas prescindir dele.

Grupioni também parece um tanto confusa quanto à natureza da descendência. ${ }^{6}$ Na página 49 , ela primeiro se refere ao "cognatismo como a forma de descendência genérica predominante" (grifado no original), para então voltar atrás na nota de rodapé número 5 , referente a esta passagem. Na nota, ela declara que embora a descendência cognática seja a forma genérica (e onde não o é?), cada grupo, na prática, toma uma inclinação patri ou matrilateral, segundo as condições locais. Não há nada demais em afirmar que cada grupo terá composição mais patri ou matrilateral de acordo com sua constituição genealógica. Infelizmente, nessa mesma sentença da autora, a lateralidade passa a unilinearidade, o tipo de erro que eu acreditava já termos há muito tempo aprendido a evitar. Para mostrar quão obstinadamente equivocada é esta posição, seria preciso repassar a vasta literatura sobre o tema da unilinearidade. Basta dizer aqui que unilinearidade não é um fenômeno estatístico. Se fosse, qualquer grupo dado poderia passar de patrilinear a matrilinear, e vice-versa, como resultado de nascimentos, mortes, migrações e outros acontecimentos. ${ }^{7}$

Vale notar que Grupioni parece também não ter conhecimento do debate teórico mais amplo para o qual MATT contribuiu, e assim é capaz de escrever: "Diante dessa perspectiva, procuramos questionar alguns pontos da caracterização típica [do tipo-ideal guianense], tais como: a suposição de que a aliança prescritiva não se assenta em nenhum esquema de descendência" (:50). As décadas de 1950-60 constituíram um período de muita discussão em torno das Estruturas elementares do parentesco, de Lévi-Strauss (1949), e supunha-se que casamentos prescritivos e estruturas elementares envolviam necessariamente troca de esposas entre grupos unilineares de descendência. Em função disso, ao ir para campo, junto aos Trio, eu tinha forte expectativa de encontrar tais grupos e esforcei-me nesse sentido - sem sucesso. Com efeito, Nur Yalman (1967), com o material de Sri Lanka, e eu, com o material dos Trio, demonstramos praticamente em simultaneidade que uma terminologia prescritiva, sem grupos de troca formalizados, já era o bastante para que tais sistemas funcionassem. Portanto, 
é curioso ver agora Grupioni afirmar que os sistemas prescritivos são compatíveis com sistemas de descendência. Tudo isso pode parecer relativamente sem importância, mas a tentativa de ressuscitar os grupos de descendência é perniciosa, como deixei claro em um artigo, "The Amerindianization of descent and affinity" (Rivière 1993). ${ }^{8}$

Há mais um aspecto do capítulo de Grupioni que eu gostaria de pôr em foco. É a questão levantada e respondida pela autora (:32-34) sobre a razão por que o trabalho de Overing e o meu retratam as estruturas sociais nativas da Guiana como o "tipo ideal" atomístico, quando a literatura histórica representa-as ricas em "intensas redes de intercasamento, migração, comércio e guerra", similarmente às descobertas do PTG. A primeira resposta apresentada é que se trata de uma coincidência histórica. As perdas demográficas e as rupturas sociais causadas pela intrusão européia teriam criado as condições descritas no "tipo ideal", mas tais condições ter-se-iam novamente modificado como resultado da crescente presença européia, a partir de meados do século XX, e do crescimento populacional. No entanto, Grupioni descarta esta explicação, argumentando que, comparado com o passado ou com o presente, o tipo ideal "transforma-se em um quadro pouco convincente, de rupturas e descontinuidades nas formas sociais que seriam características da região". Ela então sugere que o "tipo ideal" é decorrente do foco analítico do período e da crítica dos modelos africanos então correntes.

Parece-me que ela desconsiderou com demasiada rapidez a explicação histórica, e é fácil ver seus motivos para tal. Se se aceita tal explicação, é preciso também admitir que o assim chamado "tipo ideal" estava correto para a sua época, quando o ponto a ser sustentado é que ele está errado. A falha nisso está em que, conforme já foi indicado, o tipo ideal é um engodo e se o substituirmos por aquilo que ele de fato continha nas etnografias, encontraremos uma situação que, na prática, e a despeito do ideal de auto-suficiência e autonomia do povoamento local, envolve considerável movimentação, entre aldeias e além, para fins de novos povoamentos, casamentos, comércio, ritual e sociabilidade. Tal quadro mostra, sim, continuidade com a época anterior e com a situação atual. O que não significa que não tenha havido um período histórico específico, que durou uns 150 anos $^{9}$, no qual a situação era diferente - em grau, não em natureza dos períodos precedente e subseqüente. Nesse tempo, os níveis demográficos foram os mais baixos, e alguns daqueles que viajaram pela região não esperavam que a população nativa sequer sobrevivesse. O que disso resultou, então, foram povoamentos pequenos e dispersos. No entanto, as populações ainda se mantinham em contato e havia, pelos motivos que acabamos de ver, considerável movimentação entre eles. Que isso se tenha dado em intensidade inferior à das condições anteriores e posteriores, é simples decorrência da situação demográfica: havia poucas pessoas para tanto.

Há duas observações suplementares a esse respeito. Em primeiro lugar, sabemos que durante todo esse período de 150 anos grandes povoamentos ameríndios formaram-se e voltaram a dispersar-se, principalmente como resultado de influências externas. Eles por vezes resultavam de coerção, como foi documentado por Farage (1991) em relação ao rio Branco no final do século XVIII; por vezes, formavam-se voluntariamente, como a grande aldeia de Pirara, na fronteira do Brasil com a Guiana Inglesa, nos anos 1830 (ver Rivière 1995). Exemplo particularmente adequado é 
o dos Ye'cuana, que mais de uma vez oscilaram entre um padrão disperso e um povoamento melhor consolidado por efeito de influências externas (ArveloJiménez 1973).

O segundo ponto a acrescentar referese especificamente à situação entre os Waiwai e os Trio nos anos $1960 .{ }^{10}$ Como resultado da maior presença de não-indígenas, principalmente missionários, o padrão de povoamento nessa área passou por uma mudança dramática. A distribuição anterior, em pequenas aldeias enfileiradas a distâncias regulares de cerca de um dia de viagem, deu lugar a centros populacionais maiores e mais espaçados. Um dos efeitos daí decorrentes foi a redução no grau de movimentação na área, simplesmente porque ficou muito mais difícil viajar de um lugar a outro. Assim, por exemplo, a interação entre Waiwai e Trio quase terminou; os Waiwai transferiram-se em sua maioria para o alto Essequibo, e a mais próxima aldeia dos Trio ficava em Alalaparu; as aldeias que ficavam ao longo do caminho, nas quais era antes possível pernoitar ou demorar-se um pouco, foram abandonadas. Essa situação durou pouco tempo; uma população em rápido crescimento intensificou, então, o contato com o mundo exterior e um retorno parcial a um modelo mais disperso permitiu que velhos padrões de comunicação se reafirmassem. De fato, muitos padrões novos apareceram, inclusive um número crescente de Trio vivendo e trabalhando em Paramaribo.

Tudo isto está documentado na literatura que consta na bibliografia do volume, e faz ver quão seletiva teve de ser a leitura desse material para se poder criar o "tipo ideal". O que não quer dizer que a população nativa daquela área não tivesse a opinião de que a segurança estava no próprio povoado, e o perigo, fora. Quase todos os etnógrafos reconheceram esse modo de ver, mas ao mesmo tempo descrevem sua inadequação e fazem referência aos numerosos mecanismos - desde a necessidade de achar uma esposa, até o diálogo cerimonial - que favorecem e facilitam a interação externa.

Tenho bem menos a dizer sobre as outras três contribuições ao volume. Em relação ao capítulo de Gabriel Coutinho Barbosa, "Das trocas de bens", impressiona a circunstância bastante paradoxal de ele extrair tanto material de etnógrafos que aparentemente nada têm a dizer sobre a interação no interior dos grupos ameríndios, entre tais grupos, e com outros de diferentes backgrounds étnicos. Posso imediatamente e sem esforço pensar em muitas outras fontes relevantes, cujo emprego teria melhorado bastante o capítulo. Para dar um único exemplo, há o trabalho de Brian Ferguson, Yanomami warfare (1995), um dos mais detalhados relatos de um longo período de interação entre guerra, comércio, casamento e acusações de feitiçaria. Barbosa também estabelece uma relação bem curiosa entre escassez e preferência numa seção a elas devotada ("Da escassez às preferências":78-83). Elas não são excludentes, e a preferência, onde há escolha possível, pode ser exercida em presença da escassez. Em situações em que há mais de uma fonte para suprir necessidades, pode-se exercer a escolha, a preferência por objetos $\mathrm{A}$ e não $\mathrm{B}$. A razão para a preferência pode muito bem ser expressa em termos de qualidade do produto, mas ela pode ter algo a ver com a escolha por fazer negócio com determinada pessoa, e não outra. Além do mais, é possível entrar numa relação de comércio não pela escassez do objeto material, mas em função das relações que o comércio faz surgir. Como aparte, gostaria de acrescentar que a "economia simbólica da predação", ou "preensão", como Eduardo Viveiros de Castro (comu- 
nicação pessoal) prefere agora chamar, também é parcialmente impulsionada pela noção de "escassez": a necessidade e o controle de nomes, almas e outros bens simbólicos. É isso, afinal, que está na raiz da noção de "economia".

Rogério Duarte do Pateo, em seu capítulo sobre "Guerra e devoração", recorre a muita etnografia Yanomami, mas o livro de Ferguson aparece apenas na bibliografia. Novamente, ele está determinado a separar o assim chamado "tipo ideal" de tudo aquilo que veio antes e depois. "Como vimos acima, a distância sociológica existente entre as sociedades que habitavam as Guianas até pelo menos o século XVIII e os grupos pretensamente atomistas contemporâneos parece menos acentuada quando uma série de aspectos estruturais, revelados pela etnologia produzida sobre a região, são levados em conta" (:145). Já respondi, acima, a essa posição, mas repito que a "acentuação" só é alcançada através da recusa em ler o que foi escrito e em avaliar bem o impacto que o colapso demográfico teve sobre as sociedades da região.

Contando 76 páginas, "Sobre a ação xamânica", de Renato Sztutman, é com folga a unidade mais longa do livro, e também a de mais largo escopo, trazendo material do noroeste amazônico, dos Bororo, Araweté e Guajiro, assim como da região da Guiana. Das considerações que já fiz a respeito do que escreveu, depreender-se-á que ele canta pela partitura do PTG, tal como foi orquestrada pela organizadora da coletânea. ${ }^{11}$ Mas, se tentamos ignorar a polêmica, trata-se de uma sensata revisão do xamanismo na região, que faz bom uso da vasta quantidade de material adicional, de toda a Amazônia, que vem sendo publicado sobre o assunto no último quarto de século. Em vista disso, não me surpreende que ele se refira à minha abordagem como "tímida"; pois no período do trabalho de campo o xamanismo não era praticado devido à influência missionária. O que pude apreender do xamanismo trio deveu-se apenas marginalmente à observação direta, e tive de me basear quase inteiramente naquilo que me era dito. Por isso, fico, sim, surpreso de o autor se dar ao trabalho de dedicar uma seção inteira a "As noções causais e o atomismo em Rivière". Eu diria que muito do que escrevi sobre xamanismo não é incorreto, mas excessivamente limitado em escopo. Porém, acrescentaria também que nas Terras Baixas da América do Sul o xamanismo varia muito no espaço e no tempo, e que xamãs são meramente os praticantes visíveis de um universo xamânico. Na verdade, pode-se ter este sem aquele, mas não inversamente. O papel e a função de um xamã em determinado momento e lugar responderão a um conjunto específico de condições e exigências.

Também antropólogos respondem a condições e a exigências. Seria interessante saber o que os integrantes do PTG reportariam se tivessem realizado trabalho de campo nas condições, bem diferentes, que vigoravam no interior da Guiana nas primeiras décadas da segunda metade do século XX.

\section{RÉPLICA}

\section{Denise Fajardo Grupioni, Dominique Tilkin Gallois, Gabriel Barbosa, Renato Sztutman, Rogerio Duarte do Pateo}

Peter Rivière declarou ter interrompido seu recente afastamento das atividades acadêmicas, após anos de contribuições à etnologia sul-americana, para comentar nosso livro, o que muito nos honrou. Todavia, agradecendo a réplica que nos foi oferecida pela Mana, apresentamos a 
seguir o que julgamos importante esclarecer acerca das objeções do autor.

Em Redes de Relações nas Guianas (RRG), partimos dos contrastes que emergem quando confrontamos o material etnográfico produzido sobre a região nas décadas de 1960/70 com o material histórico-etnográfico anterior, ou com os resultados das pesquisas de campo realizadas no decorrer das décadas de 1980/90 pelos integrantes da Pesquisa Temática "Sociedades Indígenas e suas Fronteiras na Região Sudeste das Guianas" (doravante Projeto Guianas), coordenada por Dominique Tilkin Gallois. ${ }^{12}$ É necessário salientar que a "Introdução" e os quatro capítulos de RRG, embora assinados por autores individuais, constituem o produto de uma reflexão coletiva, e isto justifica a recorrência de idéias ao longo de toda a coletânea. Por este mesmo motivo, optamos por uma resposta conjunta às críticas do autor de trabalhos pioneiros a respeito da região sobre a qual nos debruçamos.

Do mesmo modo que Rivière (1984:2), tomamos a região das Guianas como uma área artificialmente recortada em função de propósitos analíticos. Porém, se estendemos nosso estudo aos extremos leste e oeste da região, Rivière privilegiou a faixa centro-norte. Esta restrição de escopo comparativo, deixando de fora os Yanomami, entre outros, é justificada em Rivière (idem) pela diversidade interna inerente ao grupo, "composed of a number of subgroups among whom considerable variation exists". Rivière nos acusa de distorcer esta questão. Longe disto, o nosso ponto de vista foi baseado em suas considerações a esse respeito no Prefácio à edição brasileira de Individual and Society in Guiana (ISG), no qual reitera que a "aparente variação no interior do grupo mereceria um estudo próprio", e acrescenta "que embora os outros grupos da região possuam idéias claras sobre a troca e a interação com as pessoas, reais ou imaginárias, para além dos limites das relações de parentesco, eles, segundo parece, não formulam esquemas cosmológicos elaborados" (2001b:14; grifos nossos).

À luz destes argumentos, a passagem considerada distorcida, de volta ao seu contexto, parece mais coerente. Em RRG, afirmamos que "esse autor preferiu descartar os Yanomami, em função de seu complexo sistema multicomunitário articulado a rituais e ao xamanismo agressivo, que considera latente em outras partes da região. Porém, são justamente estas formas de troca - também muito significativas entre os grupos orientais - que nos levaram a incluir os grupos deixados de lado por Rivière na área etnográfica que construímos para abordar estes sistemas multilocais, de modo que nos foi possível abarcar os Yanomami, de um lado, bem como os Wajãpi e grupos do Uaçá, do outro" (:16).

Em seus comentários, Rivière defendese do que considera um "ataque implacável", no seu entender ancorado num conjunto de estratégias que visam fazer passar por originais idéias já apresentadas por outros especialistas da região e no desconhecimento de uma série de outros aspectos. Um desses aspectos diz respeito à noção de "tipo-ideal" guianense que, segundo ele, seria um "conceito" nosso e que, com exceção de Paul Henley (1996), nenhum outro autor que criticamos o teria utilizado. Porém, aquilo que chamamos de "modelo ideal-típico guianense" não é sequer um "conceito", baseia-se apenas no reconhecimento de que o modelo proposto por Rivière consolidou uma imagem que se tornou típica da Guiana, servindo de inspiração para uma geração de etnólogos que realizou pesquisas na região ou que dialogou com tais investigações. ${ }^{13}$

Rivière considera, contudo, que "se há um 'tipo ideal', ele é a imagem ideal que os 
próprios povos da Guiana mantêm; aquilo que muitos etnógrafos descreveram como ideais nativos, que representam a comunidade como autônoma e auto-suficiente e constituem uma perspectiva que, conforme aqueles mesmos etnógrafos invariavelmente observaram, é uma ficção". No capítulo 6 de ISG, esta perspectiva está presente no contraste entre o ideal nativo de autonomia do grupo local e o imperativo da dependência decorrente da escassez de recursos humanos que inviabilizaria a auto-suficiência tão desejada. Se bem compreendemos, o autor considera que a caracterização minimalista que criticamos corresponde ao modo pelo qual os nativos apreendem a vida em sociedade e, portanto, constitui o próprio "modelo nativo". Neste caso, somos obrigados a discordar pela simples razão de que nos recusamos a supor que os nativos guianenses vivam sujeitos a uma ficção que coube à etnologia dos anos 1960/70 desnudar. Esta recusa nos levou a questionar se esse ideal de grupo endogâmico sociologicamente homogêneo representa mesmo o "modelo nativo". A nossa aposta é que não, pois acreditamos que a "abertura ao outro" é um elemento fundamental às sociocosmologias em questão. Note-se que Viveiros de Castro já questionara o modelo comparativo de Rivière (1984), adiantando uma possibilidade que nossas pesquisas vieram a confirmar, a saber, que "o fechamento sociocosmológico guianense é muito relativo e que a abertura do grupo local ao exterior não é sempre o resultado da impossibilidade de realização de um ideal de autonomia, mas pode ser regular e desejada, inerente às premissas culturais" (1986:275, nota 7).

Os pontos de divergência entre uma e outra abordagem refletem-se nos próprios títulos dos trabalhos: Indivíduo e Sociedade, de um lado, e Redes de Relações, de outro. O primeiro destaca a insuficiência da noção de "sociedade" para pensar a Guiana, optando pelo "individualismo" e pelo "atomismo". O segundo, pautando-se na crítica à própria oposição entre "indivíduo" e "sociedade", persegue a extensão e a qualidade das relações entre pessoas e grupos para além do espaço local e visível. As divergências são de ordem teórico-metodológica e nosso principal interesse foi discutir o rendimento analítico de cada uma das abordagens.

Foi com base neste propósito que procuramos contrastar, em nossa argumentação, os aspectos relacionados ao ideal de "fechamento" dos grupos locais guianenses - priorizados nos recortes das etnografias dos anos 1960/70 - com aqueles que revelam a abertura desses grupos locais. Esse contraste não é apenas retórico, como acusa Rivière, é antes um recurso para promover o diálogo em torno da diferença entre uma abordagem que investe no estudo das relações interindividuais de co-residência e outra que aposta no estudo das redes interpessoais mais amplas, que vão além do espaço do parentesco e da cognação. ${ }^{14}$

Com o avanço de nossas pesquisas, percebemos que não bastava sair do local para o multilocal, do campo do parentesco para o campo do ritual, das trocas, da guerra e da política. Foi necessário também relevar a dimensão do tempo que, nos materiais dos anos 1960/70, afora poucas exceções, aparecia subsumida ao espaço, uma vez que na Guiana a aliança - então equacionada ao ideal de endogamia local - predominaria radicalmente sobre a descendência (Overing 1973). Outro ponto importante diz respeito à necessidade de incorporar variados tipos de relações, não apenas entre humanos, à compreensão da socialidade guianense. Além de retroceder no tempo para traçar relações, foi preciso mapear uma espécie de espaço invisível no qual 
operam diversos tipos de xamanismos muitas vezes de caráter guerreiro - fortemente engajados na produção da dinâmica sociopolítica indígena. Tanto no caso da profundidade temporal, como no caso desse espaço virtual é justamente de "modelos nativos" que se está falando. E se nos referimos à descendência foi para nos aproximarmos não de um conceito antropológico hoje "renegado" no americanismo, mas de conceitos nativos..$^{15}$

Ao expor essa dissonância, não quisemos de maneira alguma acusar, como sugere Rivière, os etnógrafos dos anos 1960/70 de estarem "simply wrong". Nosso ponto não foi desqualificar a etnologia da época, mas defender que as "lentes das redes de relações" captam dimensões que escapam às "lentes do recorte individualista-localista". O que está em jogo não é a competência dos autores que nos antecederam, mas alguns a priori teóricos que aqui procuramos explicitar. Em outras palavras, buscamos ver outras coisas que então permaneciam invisíveis a esses olhares.

\section{O caso tiriyó/tarëno}

O modo extremamente resumido como o caso tiriyó é apresentado no capítulo "Tempo e espaço na Guiana Indígena" só se justifica porque um outro texto de autoria de Denise Fajardo Grupioni foi escrito para a segunda coletânea do Projeto Guianas. ${ }^{16}$ No capítulo em questão, os exemplos tiriyó foram apresentados muito genericamente, apenas em função do propósito comparativo mais amplo priorizado na economia do texto. Porém, diante das críticas e dos questionamentos apresentados, alguns esclarecimentos fundamentais precisam ser feitos.

Em primeiro lugar, a autora refere-se aos "Tiriyó" porque é assim que essa população se tornou mais conhecida e porque esta corresponde à sua autodesignação no Brasil. Em geral, quando falam em sua própria língua, identificam-se como "Tarëno wü" ("Eu sou Tarëno", "Eu sou daqui, dessa região"). Ao se apresentar para um desconhecido, um Tarëno dirá, por exemplo: "Tarëno wü, paho Okomoyana, manko Pürouyana" ("Sou daqui, meu pai é Okomoyana, minha mãe é Pürouyana"). Assim, os Tarëno se situam no espaço e no tempo. Em termos lingüísticos, o termo tarëno corresponde a um dêitico espacial que permite situar no espaço "daqui, dessa região" as pessoas que se dizem tarëno. Por outro lado, ao informar que o pai é Okomoyana e a mãe Pürouyana, por exemplo, um Tarëno situa-se no tempo: se o seu pai é Okomoyana será porque ou o pai ou a mãe do seu pai foram Okomoyana, e assim por diante.

Percebemos, portanto, a diferença analítica entre partir do recorte étnico "tiriyó" e fazê-lo da concepção nativa de "ser tarëno". Por exemplo, encontramos hoje na composição social tanto dos Tiriyó, quanto dos Wayana, a presença dos Aramayana. Isto significa que se visitarmos os Aramayana que vivem entre os Wayana no rio Paru de Leste, eles dirão que são Wayana. E se visitarmos os Aramayana que vivem no Paru de Oeste, dirão que são Tiriyó. Desse modo, nenhum desses grupos pode ser pensado como bloco separado. Por trás de suas fronteiras, há mais a analisar do que se tem suposto, principalmente no que diz respeito ao papel dos diferentes yana ("gentes") na organização política e na sociocosmologia dos grupos na região.

É neste sentido que se afirma que os integrantes do Projeto Guianas buscaram partir das "concepções nativas em direção ao que elas nos conduzem em termos conceituais" (:37). Não se trata de pretender algum ineditismo ou de desconsiderar que isso é - e sempre foi fundamental para a antropologia. No caso do material guianense, muito já foi 
feito graças à obra de Rivière. No entanto, em seu estudo seminal sobre os Trio (Rivière 1969), é possível detectar alguns pontos obscuros, como a questão das chamadas "tribos" que se espalhavam pela região até meados do século XX e que a partir de então se transformaram nos famosos "subgrupos", dando origem aos atuais "grupos étnicos". Este é um "fantasma" que assombra os pesquisadores da região e tem sido enfrentado de diversas maneiras. Enquanto "originários" ou "formadores" de diferentes grupos étnicos regionais, os "subgrupos" receberam atenção histórica. Mas pouca e, em alguns casos, nenhuma operacionalidade foi atribuída a eles enquanto entidades sociológicas passíveis de interesse etnológico. Já foram chamados de "linhagens exógamas" por Frikel (1960) e de "clãs endógamos" por Jean Chapuis \& Hervé Rivière (2003).

Um ataque decisivo, porém, foi desferido por Rivière em sua introdução a Marriage among the Trio, na qual afirma tratar-se de "tribal remnants" que, vivendo juntos, passaram a constituir "a single group having common name, language and culture" (Rivière 1969:28). Desta perspectiva, Rivière dissolve a questão em torno de uma eventual operacionalidade dos chamados subgrupos na organização social tiriyó, com base na avaliação de que não haveria vantagem a ganhar distinguindo-os (cf. Rivière 1969:27). Em sua resenha, Rivière escreve que "em função disso, ao ir para campo, junto aos Trio, eu tinha forte expectativa de encontrar tais grupos e esforcei-me nesse sentido - sem sucesso".

É importante ressaltar que, na análise de Grupioni, também não foi encontrada a existência de "grupos nominados que atuam como trocadores de esposas", como deduziu Rivière. Aliás, aquilo que chamamos de "subgrupo", os Tiriyó chamam de "itüpü"17, termo para o qual consideram "continuação" a melhor tradução. ${ }^{18} \mathrm{Ali}$, onde procuramos "grupos" ou "subgrupos", os Tiriyó dizem existir não grupos, mas continuações de gente que se perpetuam ao longo do tempo. ${ }^{19}$ Se, num primeiro momento, a autora chegou a propor que itüpü pudesse ser definida como "grupo temporal" por contraste à noção de "grupo local", ela logo se convenceu de que seria mais profícuo investir na noção de "continuação temporal". Foi surpreendente constatar que o pertencimento a continuações temporais distintas é um importante requisito considerado na efetivação dos casamentos. ${ }^{20}$ No entanto, as especificidades em jogo não permitem falar na existência de "grupos de descendência unilinear que atuam como trocadores de esposas", mas mostram em que dimensões, no ambiente cognático, aparecem vieses ou inflexões ora matri, ora patri orientados. ${ }^{21}$

Quanto ao alerta para as imprecisões de ordem lingüística, devemos dizer que se os resultados da consulta a alguns especialistas da língua tiriyó confirmam a glosa apresentada por Rivère (1969), eles nem por isso invalidam a interpretação proposta por Grupioni. Com efeito, a palavra itüpü tem de ser usada, em seus contextos de enunciação, em conjunção com um outro nome, mas quando se isola o termo e fala-se em "uma itüpü", no sentido de "uma continuação", isto é feito apenas com o propósito de isolar a noção para explicá-la, não para reificá-la. No entanto, Rivière suspeita que se esteja reificando um termo que expressa uma relação. Mas a autora afirma que "nem de um ponto de vista hipotético, nem de um ponto de vista histórico e concreto uma itüpü pode ser pensada como uma unidade autônoma, pois uma itüpü só existe em relação com outra" (:4). Por isso, não é surpreendente que, no contexto de uso da língua tiriyó, este termo nunca apareça isolado. Da mesma forma, 
a conclusão de Carlin de que os termos imoitü e itüpü são basicamente sinônimos só confirma algo que Grupioni (2002) diz estar relacionado à relatividade do conjunto de categorias nativas de que parte para analisar o que chamou de "sistema de relações tarëno". Em suma, moitü e itüpü são sinônimos apenas à medida que todos aqueles que se consideram itüpü me ("de mesma continuação") consideram-se também moitü me ("como parentes"). Todavia, nem todos os que se têm em conta de moitü me vêem-se necessariamente como itüpü me. Nesse sentido, a idéia de itüpü põe em foco noções ligadas à identidade/diferença entre pessoas de mesma ou de distintas "continuações temporais".

\section{Troca, guerra e xamanismo}

Rivière aponta uma suposta contradição entre a afirmação de Gabriel Coutinho Barbosa de que há poucos trabalhos produzidos nos últimos cinqüenta anos sobre os intercâmbios de bens contemporâneos nas Guianas (:72) e o volume de informações utilizadas no segundo capítulo "Das trocas de bens", a maioria delas proveniente da literatura etnográfica. Contudo, Barbosa referia-se ao fato de que não há muitos estudos voltados especialmente aos intensos intercâmbios de bens na região - exceto os artigos de Coppens (1971), Thomas (1972) e ButtColson (1973), ao contrário do que ocorre com outros temas como parentesco e organização social, guerras e histórias ameríndias. Portanto, ao contrário do que sugere Rivière, Barbosa não afirmava que não existem informações sobre os intercâmbios de bens nas Guianas. Há muitos dados de qualidade a respeito, dispersos em livros, artigos e monografias voltados a outros assuntos. Por isso mesmo, o capítulo buscou sistematizar o material consultado, sem qualquer pretensão de esgotar a literatura ou as discussões a respeito, buscando propor, quando pertinente, interpretações alternativas. Nesse sentido, mostrou-se que há evidências etnográficas suficientes para refutar a tese de que tais intercâmbios seriam causados pela necessidade de adquirir artigos que não poderiam ser produzidos por falta de matérias-primas ou conhecimento técnico - algo que o próprio Rivière já notara, sem identificar, no entanto, quais "mecanismos obscuros" (1984:82) motivariam então os intercâmbios de bens.

No mais, Rivière tem toda a razão quando afirma que escassez e escolha não se opõem necessariamente, podendo encontrar-se articuladas. Cumpre lembrar, porém, que a relação entre escassez e escolhas não constitui a raiz da noção de "economia" como ele afirma, mas é o fundamento de uma corrente particular do pensamento econômico surgida na segunda metade do século XIX e dominante desde então (ver Polanyi 2000; Gregory 1982). De qualquer forma, o problema apontado no artigo não está na relação entre escassez e escolhas, mas na evidente contradição, de um lado, entre os ideais de autonomia e introversão que certos autores (dentre eles, Rivière) atribuem aos ameríndios guianenses; de outro, na preferência destes últimos em buscar certos bens e relações com povos distantes social e geograficamente (inclusive não-índios), quando esses mesmos artigos poderiam ser obtidos em suas próprias aldeias, com parentes ou pessoas próximas. Cabe indagar, portanto, se tais autores não enfatizaram demais o ideal de fechamento manifesto em diversas dimensões da vida social guianense em detrimento de um desejo não menos forte desses povos em se relacionarem com outros, independente de qualquer constrangimento material.

No capítulo "Guerra e Devoração", Rogério Duarte do Pateo estabeleceu um 
diálogo (aliás, explicitado logo no primeiro parágrafo) com estudos de cunho histórico que enfatizam a descontinuidade entre os cenários pré e pós-colombianos. Esta crítica - acompanhada por considerações acerca da utilização de observações etnográficas contemporâneas para a interpretação das fontes históricas - foi baseada no trabalho de Carlos Fausto (1992), citado na página 115 e curiosamente excluído das críticas de Rivière. O foco central do capítulo é, dessa forma, a guerra indígena, e toda a discussão nele desenvolvida demonstra que, nos dias de hoje, sua aparente ausência nas Guianas decorre de uma concepção etnocêntrica do fenômeno, que desconsidera aspectos estruturais e a dimensão cósmica de sua efetuação.

Otrechocitado duas vezes na resenhana primeira, atribuído erroneamente a Sztutman, na segunda, a do Pateo - foi, infelizmente, retirado de seu contexto. A referida "distância sociológica" entre os grupos indígenas de outrora e os atuais diz respeito, como todo o capítulo, aos aspectos explicitamente relacionados à guerra indígena. Como afirmado no parágrafo subseqüente: "Longe de negar as conseqüências nefastas da colonização, os argumentos apresentados aqui tiveram o intuito de problematizar as análises que, marcadas acima de tudo pela negatividade, reduzem as sociedades indígenas das Guianas a meras sobrevivências melancólicas de um passado glorioso" (:146). A afirmação de que o autor do capítulo desconsidera o impacto do colapso demográfico sobre as sociedades da região soa exagerada quando confrontada ao trecho acima, além de desconsiderar a passagem baseada no supracitado artigo de Fausto: "Ao caráter minimalista descrito a propósito das sociedades guianenses, encarado acriticamente por muitos pesquisadores, soma-se a idéia de uma inescapável descontinuidade entre 'modos de vida indígena' pré e pós-conquista, acreditando-se que da inegável depopulação causada pela colonização decorre uma proporcional e previsível alteração do universo cultural" (:115).

É importante notar que o capítulo, ao contrário do que afirma Rivière, buscou abranger um grande número de grupos indígenas da região, apresentando informações etnográficas sobre os padrões e as técnicas de guerra, chefia e rituais de iniciação e purificação de guerreiros entre grupos contemporâneos e históri$\cos ^{22}$ Em suma, apesar de importantes, os Yanomami não são a base do artigo. Por fim, o trabalho de Brian Ferguson (citado na pág. 126 de RRG) não possui peso maior que as citações de Ramos (1980), Lizot (1984, 1994, 1996), Alès (1984) ou Chagnon (1974) por uma simples razão: apesar de ter realizado o mais completo levantamento histórico sobre os Yanomami, Ferguson apresenta análises vinculadas ao materialismo cultural de Marvin Harris ${ }^{23}$, que possui uma orientação teórica oposta àquela do Projeto Guianas. Diante disso, a preferência foi dada a informações fornecidas por Bruce Albert (1985, 1992, 2002), além de observações etnográficas realizadas pelo próprio autor. A leitura crítica dos trabalhos de Ferguson foi feita na tese de doutoramento de Rogério Duarte do Pateo (2005), esta sim voltada à análise da guerra entre os Yanomami.

Passemos ao quarto e último capítulo, "Sobre a ação xamânica", assinado por Renato Sztutman. Quanto ao uso das análises de Dominique Gallois, em suposto detrimento dos dados de Allan Campbell, que também etnografou aspectos do xamanismo wajãpi, este se justifica pela habilidade da autora em articular o xamanismo a aspectos importantes da organização social e política. Segundo esta análise, em consonância 
com os estudos de Albert (1985) sobre os Yanomami, ambos tendo iniciado suas pesquisas nos anos 1970, não é possível entender a vida social indígena fora do esquema ritual e do xamanismo (que compreende ou está compreendido no sistema de agressões). E esta articulação era propriamente o foco do quarto capítulo de RRG. Não parece, ademais, que haja uma acusação grave no comentário de que ISG traz uma avaliação tímida do fenômeno do xamanismo guianense. Houve inclusive um cuidado de Sztutman em não ater seus comentários unicamente a ISG. Foram buscados outros textos de Rivière, como aquele publicado na Revista Mana $(7 / 2,2001$ a) em que o autor debate com as idéias de Viveiros de Castro e Philippe Descola, bem como o Prefácio à edição brasileira (2001b), em que ele avalia - de maneira bastante prudente e generosa, note-se - a distância entre os seus estudos dos anos 1960 e 70 e os estudos americanistas dos anos 1980 e 90, nos quais o xamanismo mais do que nunca se revelou um ponto central, ao menos para os amazonistas. O próprio Rivière reconhece essa ausência em ISG e avança na análise da relação entre chefia (domínio material) e xamanismo (domínio imaterial), desenvolvida ao longo de todo o capítulo 4 de RRG.

$\mathrm{O}$ autor alega que os estudos sobre xamanismo na Guiana não foram muito desenvolvidos durante os anos 1960 e 70 devido a questões de ordem histórica, como a intervenção missionária. Ora, esse quadro perdura em muitos contextos atuais e um dos pontos desenvolvidos no capítulo é justamente como pensar o xamanismo em contextos muitas vezes marcados pela presença de missionários - em que os xamãs aparentemente "desapareceram". O caso waiwai é um bom exemplo. Ao mesclar referências de Catherine Howard (2001), Rubens Caixeta de Queiroz (1999) e
Carlos Dias Jr. (2000) - cada qual realizando suas pesquisas em períodos distintos - foi possível questionar esse "desaparecimento" e, ainda, indicar caminhos para se pensar o xamanismo, o que passaria por um exame dos contextos de acusação de feitiçaria, bem como dos casos de conversão de antigos xamãs em missionários.

O contexto histórico é, obviamente, um limitador fundamental. Que as coisas se transformam, isso não podemos jamais negar; devemos, sim, entender como elas mudam antes de decretarmos a sua morte. No entanto, para além da história de contato entre índios e brancos, a defasagem entre as análises dos anos 1960/70 e dos anos 1980/90 deve ser buscada também na história da antropologia. O que nos propusemos nesta coletânea o caso do interesse pelo xamanismo é, nesse sentido, exemplar - foi reexaminar etnografias antigas através de novas etnografias e teorias. Não escrevemos nossos textos para invalidar trabalhos tão importantes do ponto de vista etnográfico e teórico, como o é ISG, mas para experimentar um novo olhar e, por conseguinte, ver outras coisas, as ainda não-vistas, como a existência de uma política do invisível tão importante quanto a relação entre sogro e genro, ou a referência a linhas temporais tão fundamentais como aquelas que se multiplicam no espaço. Por exemplo, as relações de parceria de troca, que extrapolam o campo da afinidade efetiva ou cotidiana, e o mundo da guerra, visível ou invisível, operante na formação e na dissolução das pessoas e dos coletivos guianenses.

\section{TRÉPLICA}

Para não sobrecarregar a paciência dos leitores, se ainda os há a esta altura, 
serei muito breve em meus comentários adicionais. Em um plano geral, sinto que a resposta do PTG à minha resenha tem um tom bem diferente daquele do livro resenhado.

A primeira observação geral, que deve ser repetida, é que a versão em português de ISG, publicada em 2001, não é uma edição revista e ampliada, e sim uma tradução do livro de 1984, à qual se adicionou um curto prefácio. Nele, apontei certos desenvolvimentos que se deram no período que separava as duas edições, muitos dos quais eu gostaria de levar em consideração, caso estivesse preparando uma nova edição do livro. Na verdade, ao reler o livro na ocasião, em minha primeira tentativa de redigir um prefácio para a edição brasileira, achei que havia formulado um forte argumento contra a publicação da tradução, por perceber quão necessário era revisar o original, e mesmo reescrevê-lo, em função de tudo o que viera à luz naquele período. Como presumi que a Editora da USP não ficaria muito satisfeita em publicar um livro cujo próprio autor considerasse desatualizado, refiz o prefácio, embora ainda me pareça que a insatisfação seja perceptível. O motivo para excluir os Yanomami do estudo original é exatamente aquele mencionado em 1984, a saber: por suas interessantes variações internas, eles mereciam um estudo comparativo próprio, e não outro, que supostamente teria aparecido após a publicação do meu trabalho. Da mesma forma, se eu tinha pouco a dizer sobre os povos do extremo leste da região, é porque, como mostra a bibliografia de Rede de relações nas Guianas, relativamente pouca coisa havia sido publicada a seu respeito na época. ${ }^{24}$

No que diz respeito à questão do "tipo ideal", só posso reiterar que jamais o propus, e citar aquilo que escrevi: "Não estou tentando elaborar um tipo único de organização social guianense, mas re- velar seus traços distintivos, tanto o que é variável como o invariável" (1984:5). O "tipo ideal" é um boneco que o PTG fabricou para ter a quem malhar.

Em terceiro lugar, não parece haver, da parte dos colaboradores da coletânea, a devida apreciação de quanto o contexto histórico pode modificar o modo de um povo entender e representar seu mundo. Está bem documentado o fato de que uma alteração das condições de vida tende a fazer com que as pessoas se comportem de determinada forma, e não de outra. Um bom exemplo é o de Tepoztlán, cuja comunidade pareceu pacífica e cooperativa a Robert Redfield, nos anos 1920, e que Oscar Lewis, vinte anos depois, descreveu como violenta e desconfiada. $\mathrm{O}$ fato fez surgir uma longa discussão sobre qual dos dois tinha razão, até que Peter Coy (1971) mostrou que ambas as descrições são corretas, já que mudanças nas condições demográficas, políticas e econômicas poderiam facilmente explicar tais diferenças. Que os povos da Guiana possam oscilar entre uma visão "aberta" e uma visão "fechada" de seu mundo, e responder aos efeitos disso, é um fato não apenas corriqueiro, mas bem provável. Além disso, creio que é possível demonstrar a predominância da segunda visão ao longo de um século e meio, a partir do início do século XIX, e não apenas nos anos 1960-70.

Grupioni contorna algumas questões que levantei; um artigo seu, a sair, trará supostamente todos os dados genealógicos que dão apoio às suas afirmações, e seria precipitado acrescentar comentários sobre o que ela tem a dizer. No entanto, há algumas observações que vale a pena fazer.

Em primeiro lugar, ninguém, nos anos 1960, se identificava simplesmente como Aramayana, Okomoyana, nem como membro de qualquer outro subgrupo (ou seja qual for o nome que se 
dê). Ocasionalmente, alguém poderia dizer sobre outra pessoa que os ancestrais dela eram de tal e tal subgrupo - só isso. Mais uma vez, posso pensar em boas razões históricas para o fato de que, na época, a ênfase recaísse na identidade trio, e não em outra, e para o fato de que essas outras identidades se tenham tornado bem mais importantes hoje. ${ }^{25}$ Ainda assim, terei de esperar até que o material de Grupioni esteja acessível para ver de que modo os grupos mencionados supostamente operam na organização social. No momento, eu nem mesmo compreendo como é que um indivíduo escolhe sua identidade, já que esta, de acordo com o que escreve a autora, é transmitida pelo lado materno ou paterno ("se o seu pai é Okomoyana será porque ou o pai ou a mãe do seu pai foram Okomoyana"), apesar da afirmação, na nota número 21, de que há regras bem específicas. Deve-se também notar que se ser Aramayana é determinado pela linha materna, então o casamento com a filha da irmã automaticamente acarreta casamento entre Aramayanas. Mas talvez os Trio, afinal, nem pratiquem o casamento com a filha da irmã.

Em segundo lugar, quanto à questão da itïpï, fiquei ainda mais confuso. Leio, no artigo da colaboração de Grupioni à coletânea, que itïpï são grupos nomeados, definidos por descendência paterna e nos quais se dá preferência a casamentos com outros grupos; mas ela agora o nega, embora na nota de número 21 a palavra seja usada com referência a grupos substantivos, sendo a afiliação a eles definida por descendência. Além do mais, se itïpï e imoitï são duas palavras para a mesma coisa, isto é, se são sinônimos, fica difícil entender que possam ser contrastadas representando espaço e tempo, respectivamente. Finalmente, gostaria de repetir a pergunta: se "a" itïpi é um aspecto tão importante da organi- zação social trio, por que o termo nunca aparece com esse sentido num grande corpus de mitos e na literatura sobre eles? Ao ampliar a busca além de Tarëno tamu inponopï panpira, já mencionado em meus comentários anteriores, Cees Koelewijn pesquisou para mim em Tëmeta iponopïhpë panpira, e eu corri a tradução de 1979 do Novo Testamento (Serë Kan Panpira. Kainan Ehtëto) ${ }^{26}$, constatando, mais uma vez, não haver um só caso em que itïpï ou quaisquer de suas formas gramaticais sejam empregadas do modo descrito por Grupioni.

Em resposta a Barbosa, tenho duas coisas a dizer. Em primeiro lugar, devo repetir que as etnografias dos últimos 40 anos estão cheias de exemplos de pessoas a interagirem com outras, não apenas em razão de escassez material, ou de ignorância técnica ou ritual, mas por assim quererem; por qual diferente motivo afirmariam que lhes faltam a habilidade ou a matéria-prima necessárias, até que não haja mais a fonte externa? Dos exemplos por mim citados em ISG (1984:81-85), é perfeitamente possível reconhecer que muitas trocas se dão em função da troca mesma, embora no início dos anos 1980 o mecanismo fosse obscuro. Se os etnógrafos não fizeram dessas atividades o foco de seus estudos, foi provavelmente por um bom motivo: elas não eram tão importantes. Não há nada errado, se Barbosa assim quer, em enfatizar, entre o povo da Guiana, as tendências a se voltar para fora, e não as de introversão; mas aquelas não negam a existência destas e, como já afirmei, o contexto do trabalho de campo pode influir fortemente para uma visão em detrimento da outra.

Em segundo lugar, eu não falei de nenhuma contradição entre a afirmação de Barbosa de que há poucas fontes sobre esse assunto e o fato de que seu trabalho está baseado nessas fontes; 
minhas palavras foram "circunstância bastante paradoxal". Além disso, mesmo que haja apenas um punhado de artigos exclusivamente dedicados às trocas, há grande quantidade de material disponível. Etnografias gerais não raro contêm tanta informação quanto os artigos mais exclusivos. Procure-se, por exemplo, a entrada relativa a trade ["troca", "comércio"] no índice da obra de Henley, The Panare (1982), e encontrar-se-ão quase tantas páginas dedicadas a esse assunto quanto em um dos artigos especializados. Até mesmo relatos de viajantes contêm informações vitais que testemunham a freqüência e a intensidade das trocas. Impossível não se admirar lendo os escritos dos irmãos Schomburgk, da primeira metade do século XIX, com a quantidade de trocas de longa distância que ocorriam ao mesmo tempo em que os ameríndios reclamavam do abandono de muitas rotas de comércio devido à morte das pessoas.

Isto nos leva a do Pateo, a quem peço desculpas: na resenha, descuidadamente, atribuí um trecho de sua autoria a Sztutman. Mas nunca afirmei que do Pateo não se reportou a um grande número de grupos nativos, nem que seu artigo esteja baseado em material yanomami o que só faz reforçar minha sugestão de que se leia o que está escrito. Parece-me agora curioso que a vasta quantidade de informações úteis a respeito de quase 200 anos de história, encontradas em Yanomami warfare, de Brian Ferguson (1995), foi menosprezada por discordância com sua orientação teórica. Do Pateo, por sua vez, surpreende-se com o fato de eu não criticar Carlos Fausto por uma passagem que escreveu. As referências bibliográficas estão truncadas, mas suponho que se trate do trecho na página 381 do artigo de 1992 sobre os Tupinambá27, em que se lê: "De fato, seria ingênuo desconsiderar o grau de ruptura representado pela conquista colonial; entretanto, seria igualmente ingênuo supor uma correlação simples entre demografia e complexidade sociocultural (ou sociopolítica), de tal forma que a um processo de dizimação física correspondesse uma alteração proporcional e previsível em termos culturais". E Fausto prossegue, dizendo que há um "ar de familiaridade" entre o que podemos ler nas crônicas do século XVI e o que vemos nos grupos Tupi contemporâneos, apesar da grande disparidade demográfica.

O que Fausto está afirmando aí, creio, não é muito diferente de dizer que o declínio demográfico, na escala em que se deu na América do Sul, traz mudanças, mas que não há correlação simples e mecânica entre perda populacional e mudança cultural. Se observarmos a Guiana, é bem claro que a forma de organização sociopolítica relatada a respeito da região nos últimos duzentos anos não estaria à altura do empreendimento que foi construir e controlar as complexas obras hidráulicas cujos vestígios podem ser encontrados no litoral. Temos apenas, além disso, vagas idéias de como era tal organização. Em contraste, a descrição do xamanismo no século XVIII, por Pierre Barrère, é notavelmente similar aos relatos modernos; há, com efeito, um "ar de familiaridade".

Com isso, chegamos ao artigo de Sztutman, que destaquei em minha resenha original como a mais equilibrada contribuição ao volume; não tenho nada a acrescentar aqui a respeito do xamanismo. Há, no entanto, uma questão geral adicional, relativa ao fim do último parágrafo da "Réplica", parágrafo este que me dá a impressão de ter sido escrito por Sztutman. É claro que está certo dizer que devemos reavaliar as fontes históricas e etnográficas à luz de novos conhecimentos e novas abordagens, e não tenho nenhum problema com nada do que está escrito 
aí. Mas isso está num tom bem diferente da afirmação, em Rede de relações nas Guianas, de que os etnógrafos dos anos 1960-70 erraram, a ponto de seus relatos nem mesmo se encaixarem na trajetória histórica da região. Fica sugerido que esse foi o resultado das teorias antropológicas da época, mas não resiste a um exame minucioso: os vários etnógrafos dessas décadas tinham um amplo espectro de formações teóricas e diferentes origens nacionais. ${ }^{28}$ Conformidade a alguma ortodoxia é muito mais uma característica de grupos coesos, como o PTG, que parece ter até agora, com a publicação de Rede de relações nas Guianas, evitado o debate com aqueles que critica. Os etnógrafos dos anos 1960-70 trabalharam no fim de um período de 150 anos em que a população indígena alcançou os níveis mais baixos, em que a exploração dos povos ameríndios ainda era disseminada e a maioria das comunidades tendia à introversão. Eles forneceram uma descrição precisa daquela situação.

\section{Notas}

* Redes de relações nas Guianas. 2005. Gallois, Dominique Tilkin (org.) São Paulo: Associação Editorial Humanitas/ Fapesp.

${ }^{1}$ Não me desculpo pela freqüência com que cito meu próprio trabalho, já que ele é o foco de boa parte das críticas. As citações são da versão em inglês de ISG, uma vez que Vanessa Lea chamou minha atenção para a freqüência de erros de tradução na edição em português, muitos dos quais comprometedores do sentido.

2 Esses agrupamentos de algumas aldeias entre as quais existe um alto grau de relacionamento, mas que não têm reconhecimento terminológico, parecem ser bastante comuns, não apenas na região da Guiana. Philippe Descola, por exemplo, registra o que ele chama de "nexo endogâmico" entre os Achuar, "estruturas supralocais sem denominação vernacular" (1986:19), que são claramente semelhantes em forma e função às aglomerações Trio.

${ }^{3}$ Suponho, no entanto, que o seu capítulo nesse volume seja uma tentativa de compactar a tese de doutorado em poucas páginas. Isto explicaria a existência de numerosos títulos na sua bibliografia que não correspondem a referências no texto.

${ }^{4}$ Embora a transliteração seja diferente, é claro que o itüpü de Grupioni é o meu itïpï; uma ortografia com a qual concordam tanto Eithne Carlin quanto Cees Koelewijn, entre os mais fluentes falantes não-Trio da língua.

${ }^{5}$ Deve-se acrescentar que Carlin, que tem uma versão digitalizada de Tarëno tamu inponopï panpira (Keisi s/d), original Trio de Koelewijn (1987), me informa que, embora a palavra apareça freqüentemente na forma verbal "continuar", o seu uso para se referir às relações de parentesco restringe-se ao fim da história "Aramajana epohtoponpë". Carlin (comunicação pessoal, 14 de abril de 2006) escreve a esse respeito: "há uma ocorrência na história aramajana em que é claro que itïpï é um sinônimo de -moiti: essa é a explicação para a troca matrimonial entre os Aramajana, os Aramiso, os Maraso etc. no fim da história".

${ }^{6}$ Grupioni parece ter sido muito influenciada nesse ponto pelas etnografias de povos como os Palikur e os Wajäpi que 
registram a existência de algo semelhante ao seu itüpü.

${ }^{7} \mathrm{O}$ vírus da unilinearidade espalha-se a ponto de Sztutman, no seu capítulo (:168, nota 14), transformar a minha expressão "unidades de troca bastante mal definidas, as assim chamadas patrilinhagens" em "patrilinhagens". Ele afirma ainda que Grupioni demonstrou "casos de ocorrências de inflexões de patrilinhagens no sistema cognático".

${ }^{8}$ Embora esta publicação esteja listada na "bibliografia temática", ela não é referida por nenhum dos autores no corpo do seu trabalho.

${ }^{9}$ Se retornarmos aos relatos dos viajantes do século XIX, tais como os irmãos Schomburgk ou Jules Crevaux, o quadro que eles desenham da vida ameríndia é notavelmente consistente em relação ao que foi registrado pelos etnógrafos de meados do século XX.

${ }^{10}$ Isto foi bem descrito em MATT (:51-4) e em Rivière (1966), um trabalho não incluído na bibliografia.

11 Por exemplo, ele credita a Gallois (1988:181) ter demonstrado que "entre os Wajäpi, o xamanismo não é um atributo pessoal, mas uma qualidade que deve ser possuída, apropriada e, sobretudo, cultivada". Alan Campbell afirmou exatamente isto no começo dos anos 1980. Sztutman faz referência à tese de doutorado de Campbell (que é de Oxford, e não de Cambridge, 1982), mas só a respeito da historieta sobre as pessoinhas dentro de uma máquina de escrever que fazem bater as teclas, e não à sua discussão sobre o xamanismo como uma qualidade. Lembrome claramente de Campbell ter me escrito sobre esse ponto no final dos anos 1970, enquanto ainda estava no campo.
${ }^{12}$ Este projeto foi desenvolvido no Núcleo de História Indígena e do Indigenismo da Universidade de São Paulo (NHII/USP) entre 1996 e 2003, com a participação de 20 pesquisadores e apoio da Fundação de Apoio à Pesquisa de São Paulo.

${ }^{13}$ Ao se basear em Rivière (1984), Århem contrasta o "prototypical Guiana settlement" (1989:17) com a "typically Tukano social structure" e como um "intermediary type: the "wild' Maku" (idem:8). O autor remete a "tipos" da mesma forma que falamos em "tipo-ideal" para nos referirmos ao modelo proposto por Rivière (1984).

${ }^{14}$ Não se pode dizer que interações mais amplas foram desconsideradas pelas etnografias anteriores. O ponto é que elas ficaram de fora dos modelos analíticos. E, nesse sentido, não receberam o mesmo peso explicativo que em nossas pesquisas.

${ }^{15}$ A afirmação de Grupioni, no primeiro capítulo de RRG, de que é necessário pensar critérios de associação que levem em conta a profundidade temporal encontra eco em outras análises recentes. Este é o caso do Grupo de Trabalho sobre "Estudos de Descendência", coordenado por Isabella Lepri e Vanessa Lea, em julho de 2006, integrando as atividades do Seminário dos Americanistas em Sevilha. Na ementa do GT consta o seguinte objetivo: "retomar a noção de descendência, mas de uma perspectiva ameríndia, buscando desenvolver um modelo de qualidades herdáveis e transmissíveis baseadas em evidências etnográficas, que englobam tanto o domínio substantivo como o não-substantivo, onde nomes, espíritos xamânicos, prerrogativas rituais e outras formas de pertencimento podem ser vistas como passando de um grupo ao outro". 
${ }^{16}$ O texto "Tempo e Espaço no Sistema de Relações Tarëno", de Grupioni, que integra esta segunda coletânea (no prelo), apresenta um resumo dos principais argumentos de sua tese de doutorado (Grupioni 2002), em que constam todos os dados e gráficos necessários para sustentar a interpretação proposta.

${ }^{17}$ Utilizamos aqui a grafia adotada pelos próprios Tiriyó do Brasil.

${ }^{18}$ À medida que se aprofundou no estudo da noção de itüpü, Grupioni (2002) pôde comprovar o rico e amplo escopo semântico desta noção que, como dizem os Tiriyó, "serve para tudo que existe no mundo", desde os leitos dos rios que correm, os caminhos que seguem, as árvores e os corpos animados que crescem, até os homens que se tornam tüpüye ao casar, ou seja, em condição de "continuarem-se" por meio de seus filhos e netos.

${ }^{19}$ As menções aos Aramayana, que encontramos em fontes que vão desde o século XVIII até hoje, indicam que, de alguma forma, a qualidade de pertencimento à Aramayana itüpü, por exemplo, tem sido transmitida — de uma geração à outra - ao longo dos últimos séculos.

${ }^{20}$ Num levantamento estatístico das "continuações" a que diziam pertencer cada uma das 316 pessoas casadas no conjunto populacional estudado, Grupioni constatou que apenas 7\% (24 pessoas) encontravam-se casados com cônjuges que diziam pertencer à mesma "continuação". Ao lado deste caráter relativamente constante da exogamia de itüpü, verifica-se um caráter mais circunstancial quanto às tendências endogâmicas e/ou exogâmicas das aldeias, que variam conforme seu desenvolvimento (ver Grupioni, 2002).
${ }^{21}$ Em sua estadia entre os Tiriyó, em agosto de 2005, Grupioni confirmou que diferentemente dos homens Pürouyana e Okomoyana que costumam atribuir seu pertencimento a estas itüpü por herança paterna, os Aramayana e os Saküta afirmam definir a que itüpü pertencem por linha materna. Isto mostra que mais do que ausência de operacionalidade da noção de descendência, o que há na região é um vasto campo ainda a ser explorado no que tange às especificidades propriamente ameríndio-guianenses desta noção.

${ }^{22}$ Entre eles: Palikur, Galibi (ou Kari'na), Aparai, Wayana, Wajãpi, Yanomami (Yanomam e Sanumá), Yekuana, Waiwai, Kaxuyana, Taurepag e Zo'e, além dos Manao, Lokono, Yao, Puinave, entre outros.

${ }^{23}$ Sobre esse ponto ver, sobretudo, a noção de "etic behavioral approach to war" (Ferguson, 1995a:13-16; 2001), além de seus trabalhos: 1995a (caps. 1 e 2); 1995b, 1999, 2000, 2001.

${ }^{24}$ Em sua "Réplica", Gallois cita o Prefácio da edição brasileira de 2001 (:14), para dar apoio à afirmação de que os Yanomami foram por mim excluídos em razão de não haver relato, quanto a outros povos da Guiana, do elaborado sistema cosmológico descrito a seu respeito. Os mais perspicazes notarão que a citação não está completa.

${ }^{25}$ Como palpite especulativo, perguntome sobre até que ponto a importância dos subgrupos não foi criada por pessoas de fora, que apareciam para perguntar sobre eles. Guardo suspeita similar com relação à descendência. A maioria das pessoas provavelmente tem alguma idéia de descender de outras, que as antecederam; mas a importância disso poderia facilmente aumentar em função de constantemente haver etnógrafos querendo saber mais sobre o assunto. 
${ }^{26}$ Com a ajuda de um livro de concordância bíblica, procurei todas as ocorrências da palavra tribo.

${ }^{27}$ Em Rede de relações nas Guianas, do Pateo refere-se ao trabalho de Fausto como de 1998 e, na "Réplica", como de 1988, sem informar os números de página. Minha cópia do trabalho tem data de 1992.

${ }^{28}$ Por exemplo, a monografia de ArveloJiménez (1971) sobre os Ye'cuana não faz referência ao meu trabalho, embora ambos retratemos tipos muito similares de sociedade.

\section{Referências bibliográficas}

ALBERT, Bruce. 1985. Temps du sang, temps des cendres: répresentation de la maladie, système rituel et espace politique chez les Yanomami du Sud-est. Tese de doutorado, Université Paris X. 1992. "Fumaça do metal: história e representação do contato entre os Yanomami". Anuário Antropológico, 89:151-190.

. 2002. "O ouro canibal e a queda do céu. Uma crítica xamânica da economia política da natureza (Yanomami)". In: B. Albert \& A. Ramos (orgs.), Pacificando o branco: cosmologias do contato no norte-amazônico. São Paulo: IMESP/IRD/ Ed. UNESP. pp. 239-274.

ALÈS, Catherine. 1984. "Violence et ordre social dans une société amazonienne. Les Yanomamü du Venezuela". Etudes Rurales, 95/6:89-114.

ÅRHEM, Kaj. 1989. "The Makú, the Makuna and the guiana system: transformation of social structure in northern lowland South America". Ethnos, 1-2:5-22.

ARVELO-JIMÉNEZ, Nelly. 1971. Political relations in a tribal society: a study of the Ye'cunan Indians of Venezuela. Ph.D. Thesis, Cornell University.

1973. The dynamics of the Ye'cuana ("Maquiritare") political system: stability and crises. Copenhagen: IWGIA.

BUTT-COLSON, Audrey. 1973. "Intertribal trade in the Guiana highlands". Antropológica, 34:5-69.

CHAGNON, Napoleon. 1974. Studying the Yanomamö. New York: Holt, Rinehart and Winston.

CHAPUIS, Jean \& RIVIÈRE, Hervé. 2003. Wayana eitoponpë. (Une) histoire (orale) des Indiens Wayana. Cayenne: Ibis Rouge Editions.

COPPENS, Walter. 1971. "Las relaciones comerciales de los Yekuana del Caura-Paragua". Antropológica, 30:28-59.

COY, Peter. 1971. "A watershed in mexican rural history: some thoughts on the reconciliation of conflicting interpretations". Journal of Latin American Studies, 3:39-57.

DESCOLA, Philippe. 1986. La nature domestique. Symbolisme et praxis dans l'écologie des Achuar. Paris: Editions de la Maison des Sciences de L'Homme.

DIAS Jr., Carlos M. 2000. Próximos e distantes: estudo de um processo de descentralização e (re)construção de relações sociais na região Sudeste das Guianas. Dissertação de mestrado, USP, São Paulo.

DUARTE DO PATEO, Rogério. 2005. Niyayu: relações de antagonismo e aliança entre os Yanomam da Serra das Surucucus (RR). Tese de doutorado, PPGAS/USP, São Paulo. 
FARAGE, Nádia. 1991. As muralhas dos sertões: os povos indígenas no Rio Branco e a colonização. Rio de Janeiro: Paz e Terra/ ANPOCS.

FAUSTO, Carlos. 1992. "Fragmentos de história e cultura tupinambá: da etnologia como instrumento crítico de conhecimento etno-histórico". In: M. Carneiro da Cunha (org.), História dos índios no Brasil. São Paulo: Companhia das Letras. pp. 381-96.

FERGUSON, Brian. 1995. Yanomami warfare: a political history. Santa Fe: School of American Research Press. 1995b. "Infraestructural determinism". In: M. F. Murphy \& M. L. Margolis (orgs.), Science, materialism end the study of culture. Gainsville: University of Florida Press. pp. 2138.

1999. "A savage encounter: western contact and the Yanomami war complex". In: B. Ferguson \& N. L. Whitehead (orgs.), War in the tribal zone: expanding states and indigenous warfare. 2a .ed. Santa Fe: School of American Research Press. pp.119-127.

2000. "The causes and origins of 'primitive warfare': on evolved motivations of war". Anthropological Quarterly, 73:159-64. 2001. "Materialist, cultural and biological theories on why Yanomami make war". Anthropological Theory, 1(1):99-116.

FRIKEL, Protásio. 1960. "Os Tiriyó: notas preliminares". Boletim do Museu Paraense Emílio Goeldi, 9. Nova Série: Antropologia.

GALLOIS, Dominique. 1988. O movimento na cosmologia waiãpi: criação, expansão e transformação do universo. São Paulo, Tese de doutorado, USP.

GREGORY, Christopher. 1982. Gifts and commodities. Londres: Academic Press.
GRUPIONI, Denise F. 2002. Sistema e mundo da vida tarëno: um "jardim de veredas que se bifurcam" na paisagem guianesa. Tese de doutorado, PPGAS/USP, São Paulo. 2006. "Tempo e espaço no sistema de relações tarëno". In: Dominique Gallois (org.), Sociedades indígenas e suas fronteiras na região Sudeste das Guianas. São Paulo: Humanitas/Fapesp/NHII-USP. Série Redes Ameríndias, v.2 (no prelo)

HENLEY, Paul. 1982. The Panare. Tradition and change on the amazonian frontier. New Haven \& London: Yale University Press. 1996. "South indian models in the amazonian lowlands". Manchester Papers in Social Anthropology, 1:1-80.

HOWARD, Catherine. 2001. Wrought identities: the Waiwai expeditions in search of the "unseen tribes" of Northern Amazonia. Ph.D. thesis, University of Chicago, Chicago.

KEISI [Cees Koelewijn]. s/d. Tarëno tamu inponopï panpira. Leusden: Algemeen Diakonaal Bureau.

KOELEWIJN, Cees. 1987. Oral literature of the Trio indians of Surinam. Dordrecht \& Providence: Foris Publications.

LÉVI-STRAUSS, Claude. 1949. Les structures élémentaires de la parenté. Paris: PUF

LIZOT, Jacques. 1984. "Histoire, organization et évolution du peuplement Yanomami". L'Homme, 24(2):5-40. 1994. "On warfare: an answer to N. A. Chagnon". American Ethnologist, 21(4):845-62. 1996. "Sang et statut des homicides chez les Yanomami centraux". In: Michel Cartry \& Marcel Detienne (orgs.), Destins de meurtriers, cahier 14 de Systèmes de Pensée an Afrique Noir, pp.105-126. 
OVERING, Joanna. 1973. "Endogamy and the marriage alliance: a note on continuity in kindred-based groups". Man, 8(4):555-570. . 1992. "Wandering in the market and the forest: an amazonian theory of production and exchange". In: R. Dilley (org.), Contesting markets: a general introduction to market ideology, imagery and discourse. Edinburgh: Edinburgh University Press. pp.182-202.

POLANYI, Karl. 2000. A grande transformação: as origens de nossa época. Rio de Janeiro: Campus.

QUEIROZ, Rubens C. de. 1999. "A saga de Ewká: epidemias e evangelização entre os Waiwai". In: Robin Wright (org.), Transformando os deuses: os múltiplos sentidos da conversão entre os povos indígenas no Brasil. Campinas: Ed. da Unicamp/ Fapesp. pp. 255-284.

RAMOS, Alcida. 1980. "Sanumá, Maiongong". In: Hierarquia e simbiose: relações intertribais no Brasil. São Paulo: Hucitec. pp.19-130.

RIVIÈRE, Peter. 1966. "A policy for the Trio indians of Surinam". Nieuwe West-Indische Gids, 45:95-120. 1969. Marriage among the Trio: a principle of social organization. Oxford: Clarendon Press. . 1984. Individual and society in Guiana: a comparative study of amerindian social organization. Cam- bridge: Cambridge University Press. [ed. bras.: O indivíduo e a sociedade na Guiana: um estudo comparativo da organização social ameríndia. São Paulo, Edusp, 2001.] 1993. "The amerindianization of descent and affinity". L' Homme, 126-8:507-16.

1995. Absent-minded imperialism. Britain and the expansion of empire in nineteenth-century Brazil. London: Tauris Academic Studies. . 2001a. "A predação, a reciprocidade e o caso das Guianas". Mana. Estudos de Antropologia Social, 7(1):31-53.

. 2001b. "Prefácio à edição brasileira". In: Indivíduo e sociedade na Guiana. São Paulo: Edusp. pp. 9-18.

Serë Kan Panpira. Kainan Ehtëto. 1979. Coral Gables: Worldteam.

TËMETA WETARU. 2003. Tëmeta iponopïhpë panpira. Katwijk: Van den Berg.

THOMAS, David J. 1972. "The indigenous trade system of southeast estado Bolivar, Venezuela". Antropologica, 33:3-37.

VIVEIROS DE CASTRO, Eduardo. 1986. "Sociedades minimalistas: a propósito de um livro de Peter Rivière". Anuário Antropológico/1985:265-281.

YALMAN, Nur. 1967. Under the Bo tree. Berkeley and Los Angeles: University of California Press.

Peter Rivière é professor emérito da Universidade de Oxford e membro emérito do Linacre College, Oxford. E-mail: <peter.riviere@talktalk.net>.

Dominique Tilkin Gallois, Denise Fajardo Grupioni, Gabriel Barbosa, Renato Sztutman e Rogerio Duarte do Pateo são pesquisadores do Núcleo de História Indígena e do Indigenismo - NHII/USP. E-mails: <dogallois@superig.com.br; de.fajardo@gmail.com;ggabrielbar@gmail.com;sztutman@uol.com.br;rogerio@ socioambiental.org $>$. 